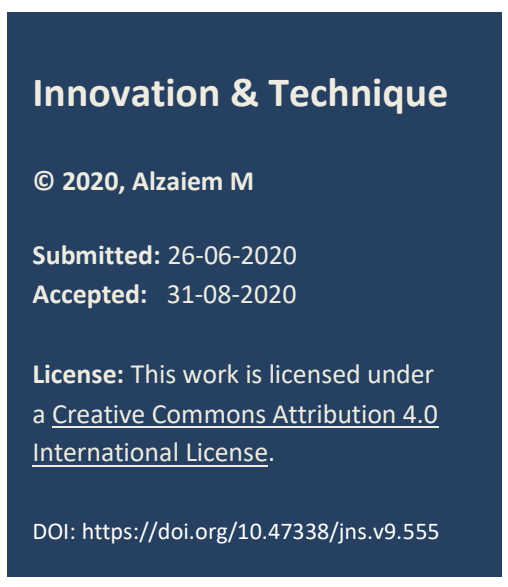

\title{
Esophageal elongation using Foley catheter in long-gap esophageal atresia
}

\author{
Maher Alzaiem
}

Department of Pediatric Surgery, Maternity and Children Hospital, Mecca, Kingdom of Saudi Arabia

Correspondence*: Dr. Maher Alzaiem, MD, CU, ABPS. Pediatric Surgery Department, Maternity and Children Hospital, Mecca. P.O: 13255, Kingdom of Saudi Arabia. E-mail: maher_zaiem@hotmail.com

\author{
KEYWORDS \\ Esophageal atresia, \\ Tracheoesophageal fistula, \\ Long-gap esophageal atresia, \\ Esophageal elongation, \\ Esophagus
}

\begin{abstract}
Esophageal atresia/tracheoesophageal fistula (EA/TEF) is a rare congenital anomaly that poses major surgical challenges, particularly when the distance between the two esophageal ends exceeds $3 \mathrm{~cm}$. Many surgical techniques are advocated for bridging the gap between the two esophageal ends. In this paper, we propose a simple and effective technique to elongate the esophagus in the long gap EA. This technique has successfully been applied in two infants with type $\mathrm{C}$ EA/TEF, where a primary end to end esophageal anastomosis was not feasible. The technique uses two Foley catheters for traction of upper and lower esophageal ends in long-gap EA/TEF. This method helps preserve the native esophagus, providing comfortable suction of the upper esophageal pouch, and assuring postoperative continuous feeding through the lower esophageal segment.
\end{abstract}

\section{INTRODUCTION}

Esophageal atresia and tracheoesophageal fistula $(\mathrm{EA} / \mathrm{TEF})$ is a congenital anomaly with an incidence of 1 in 3000 to 4000 live birth.[1,2] Long-gap esophageal atresia (LGEA) is defined as a gap of $>3 \mathrm{~cm}$ or $>2$ vertebral bodies height between the two esophageal stumps.[3,4] Those two stumps are surgically far apart to perform the primary anastomosis. Different techniques have been reported in the literature to bridge this gap, including circular myotomy of the proximal esophageal stump (Livaditis procedure), and mobilization of the distal pouch.[5-6] Esophageal replacement surgery has also been widely used such as; gastric tube reconstruction [7], gastric pull-up procedure [8], and jejunal or colonic interposition. $[9,10]$ There is no consensus about the optimal procedure for the esophageal replacement in LGEA, however preserving the native esophagus is considered a priority. Delayed primary repair of long gap esophageal atresia preserving the native esophagus was described by Foker et al. [11] in 1997 using external traction sutures for esophageal lengthening that can also be accomplished thoracoscopically.[12]

In this report of two cases, we describe a modification of a lengthening technique in patients with LGEA, aiming to avoid the complications of sutures cutting through the esophageal tissue. This method uses two Foley catheters which help in traction of the two esophageal stumps and serve as transthoracic esophagostomy and feeding esophago-gastrostomy.

\section{TECHNIQUE}

We employed this technique in two male infants of long-gap EA/TEF. The first baby was premature (33 weeks of gestation) with very low birth weight (1300 g) whereas, the second baby was born at 37 weeks of gestation with low birth weight (1900 g). Both were operated through right postero-lateral thoracotomy using an extrapleural approach. The lower esophageal segment was identified, the tracheoesophageal fistula was divided, and the proximal pouch was mobilized and dissected into the neck. After mobilization, the assessment of the gap between the two esophageal pouches showed a gap of $3-4 \mathrm{~cm}$ in both. The primary anastomosis was not feasible; therefore, we decided to elongate the esophagus using Foley catheters to apply traction.

A Foley catheter $(\mathrm{Fr} 8)$ was introduced into the chest cavity through intercostal space above the thoracotomy incision. Its distal end was placed in the distal esophageal pouch and the balloon was inflated using $1.5 \mathrm{ml}$ of contrast material. The catheter was fixed 
inside the esophagus using purse-string suture with $\operatorname{Vicryl}^{\mathrm{TM}}(3 / 0)$ placed at the esophageal stump end to close it tightly around the body of the Foley catheter to allow traction of the distal esophagus. A similar technique was applied to the upper esophageal pouch by insertion of a second Foley catheter to the chest cavity through the 6th intercostals space below the main thoracotomy incision (Fig.1). A chest tube was placed between the two esophageal ends to address any eventual leak around the catheters. At this point, the thoracotomy was closed with the two Foley catheters exteriorized through the thoracic wall above and below the thoracotomy incision, keeping them in traction and fixed to the skin separately. Postoperatively, the infants were kept paralyzed. The Foley catheter in the upper esophageal pouch was kept in place to apply traction and to serve as trans-thoracic esophagostomy, by keeping it connected to a low-pressure suction to drain the saliva from the upper esophageal pouch. The other catheter in the distal esophagus applied continuous traction of the lower esophagus in addition to serving as an esophago-gastrostomy tube feeding.

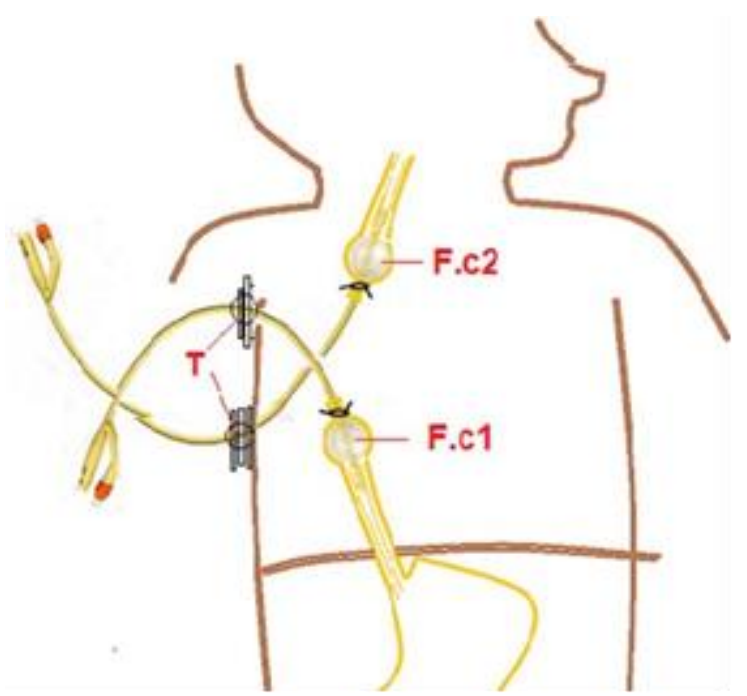

Figure 1: An illustration of the technique. F.c1 (Foley catheter 1); F.c2 (Foley catheter 2); Pieces of traction tubes for incrementing tractions.

The traction on catheters helped in the elongation of both esophageal ends. The traction was achieved by the daily insertion of small tubes between the exit site of the catheters and the fixation point of the catheters (Fig.2). Repeated daily chest x-ray showed the progress of elongation of esophageal ends as measured by the distance between contrast filled Foley catheter bulbs (Fig.3).

The close approximation was achieved on the 8th and 10th day, respectively. By that time, a second thoracotomy was performed, the Foley catheters were removed, a rim of tissue of the lower esophageal segment at the site of the purse-string sutures was re- sected, and an end to end esophageal anastomosis was performed using interrupted 5-0 Vicryl ${ }^{\mathrm{TM}}$ sutures over a trans-anastomotic nasogastric tube. An oral contrast study performed on the 7 th postoperative day showed the free passage of contract, thus oral feeding was established gradually. Both infants recovered well and had intact esophagus. Both had gastroesophageal reflux postoperatively. Both are thriving well on a follow-up of 7 and 12 months, respectively.

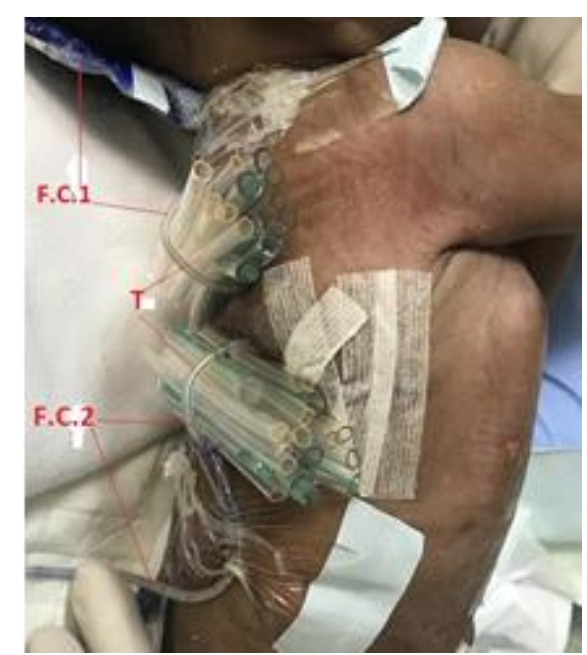

Figure 2: Showing the traction tubes under the exteriorized Foley catheters
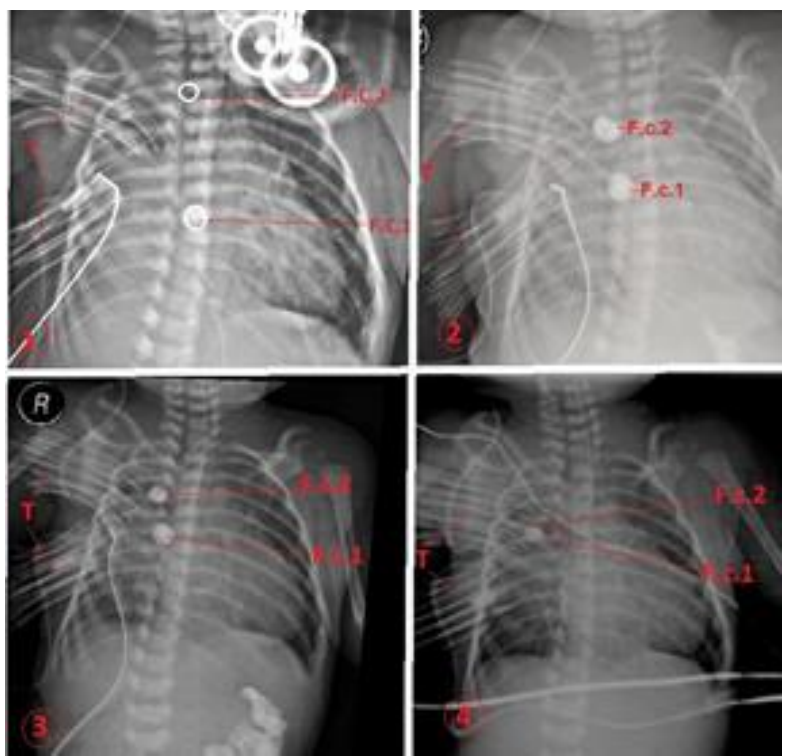

Figure 3: Serial chest x-rays (1-4) showing the progress of the balloons of the catheters.

\section{DISCUSSION}

LGEA poses a challenge for pediatric surgeons when primary anastomosis cannot be performed during thoracotomy. Babies with LGEA are traditionally managed by esophagostomy and gastrostomy, followed by esophageal replacement through jejunal or colonic interposition, or a gastric tube or gastric pullup.[7-10] However, the preservation of the native 
esophagus has always remained a priority to avoid the long term complications of the gastric or intestine inter-positioning. Therefore, Foker's description [11] of inducing growth of the esophageal pouches using continuous stitches traction on both esophageal ends for several days has refreshed the idea of preserving the native esophagus. Over the last 20 years, Foker's technique of esophageal elongation has gained attention, and it has been used in many centers.[13, 14] Nevertheless, Foker's technique has been criticized for its high complication rate, particularly interruption of the stitches through the esophagus.[15] Also, Foker pointed out that superficial sutures could tear out under tension while deep sutures could invade the lumen and cause perforation, leak, and infections. $[11,16]$

In our technique, the traction was maintained with soft balloons of the Foley catheters which were secured by the purse string stitches around the catheters that can overcome the problem of suture cutthrough the esophagus as seen in Foker's technique. Furthermore, the two Foley catheters used for traction in the proposed technique have an additional role in the management of these EA sick babies. The first catheter, which is inserted in the lower esophagus, is used as a trans-thoracic esophago-gastrostomy feeding tube, and the second catheter -which is inserted in the upper esophagus -has an important role of trans-thoracic esophagostomy to drain the saliva using low-pressure suction.

There is always a concern of pressure necrosis at the level of the two esophageal ends and the occurrence of an eventual intra-thoracic esophageal leak, however, having less duration of traction, and the placement of the chest tube at the site of the esophageal ends should address and minimize these risks. Alt-

\section{REFERENCES}

1. Shaw-Smith C. Oesophageal atresia, tracheoesophageal fistula, and the VACTERL association: review of genetic and epidemiology. $\mathrm{J}$ Med Genet. 2006; 43:545-54

2. Al-Zaiem M, Rahim TA, Al Saed A. Incidence of congenital anomalies in Holy Makkah. Saudi Med J. $1997 ; 18: 356-8$.

3. Castilloux J, Noble AJ, Faure C. Risk factors for shortand long-term morbidity in children with esophageal atresia. J Pediatr. 2010; 156:755-60.

4. Bagolan P, Valfrè L, Morini F, Conforti A. Long-gap esophageal atresia: traction-growth and anastomosisbefore and beyond. Dis Esoph. 2013; 26:372-9.

5. Lai JY, Sheu JC, Chang PY, Yeh ML, Chang CY, Chen CC. Experience with distal circular myotomy for longgap esophageal atresia. J Pediatr Surg. 1996; 31:15038.

6. Davison P, Poenaru D, Kamal I. Esophageal atresia: primary repair of a rare long gap variant involving distal pouch mobilization. J Pediatr Surg. 1999; 34:1881-3. hough this technique was applied in a case of EA/TEF, we think that it might be used as a primary procedure in cases of long gap isolated esophageal atresia.

The report has a limitation of small sample size, noncomparative design, and lack of long-term outcomes. As the outcome of only two cases was described therefore, further comparative studies with good sample size and adequate postoperative long-term follow-up can help evaluate the ultimate outcome of this technique.

In conclusion, we have proposed a new technique of traction of esophageal ends in LGEA. In addition to the preservation of the native esophagus without much risk of cut-through of traction sutures, the Foley catheters can also be used to tube-feed the baby through the lower esophageal pouch, and act as a suction catheter for saliva from the upper esophageal pouch.

\section{Acknowledgements: $\mathrm{Nil}$}

Conflict of Interest: None declared.

\section{Source of Support: Nil}

Consent to Publication: Author(s) declared taking informed written consent for the publication of clinical photographs/material (if any used), from the legal guardian of the patient with an understanding that every effort will be made to conceal the identity of the patient, however it cannot be guaranteed.

Author Contributions: Author(s) declared to fulfill authorship criteria as devised by ICMJE and approved the final version. Authorship declaration form indicating individual contribution, submitted by the author(s), is available with the editorial office.

7. McCollum MO, Rangel SJ, Blair GK, Moss RL, Smith BM, Skarsgard ED. Primary reversed gastric tube reconstruction in long gap esophageal atresia. J Pediatr Surg. 2003; 38:957-62.

8. Sharma S, Gupta D. Primary gastric pull-up in pure esophageal atresia: Technique, feasibility and outcome. A prospective observational study. Pediatr Surg Int. 2011; 27:583-5.

9. Spitz L. Esophageal atresia. Lessons I have learned in a 40-year experience. J Pediatr Surg. 2006; 41:163540.

10. Hamza AF. Colonic replacement in cases of esophageal atresia. Semin Pediatr Surg. 2009; 18:40-3.

11. Foker JE, Linden BC, Boyle EM, Marquardt C. Development of a true primary repair for the full spectrum of esophageal atresia. Ann Surg. 1997; 226:533-43.

12. van der Zee DC, Vieira-Travassos D, Kramer WL, Tytgat SH. Thoracoscopic elongation of the esophagus in long gap esophageal atresia. J Pediatr Surg. 2007; 42:1785-8. 
13. Lopes MF, Reis A, Coutinho S, Pires A. Very long gap esophageal atresia successfully treated by esophageal lengthening using external traction sutures. J Pediatr Surg. 2004; 39:1286-7.

14. Al-Qahtani AR, Yazbeck S, Rosen NG, Youssef S, Mayer SK. Lengthening technique for long gap esophageal atresia and early anastomosis. J Pediatr Surg. 2003; 38:737-9.
15. Till H, Sorge I. Oesophageal elongation with traction sutures (FOKER procedure) in a newborn baby with long-gap oesophageal atresia (LGEA): May be too early, maybe too dangerous? Afr J Pediatr Surg. 2013; 10:379-80.

16. Foker JE, Kendall TC, Catton K, Khan KM. A flexible approach to achieve a true primary repair for all infants with esophageal atresia. Semin Pediatr Surg. 2005; 14:8-15. 